
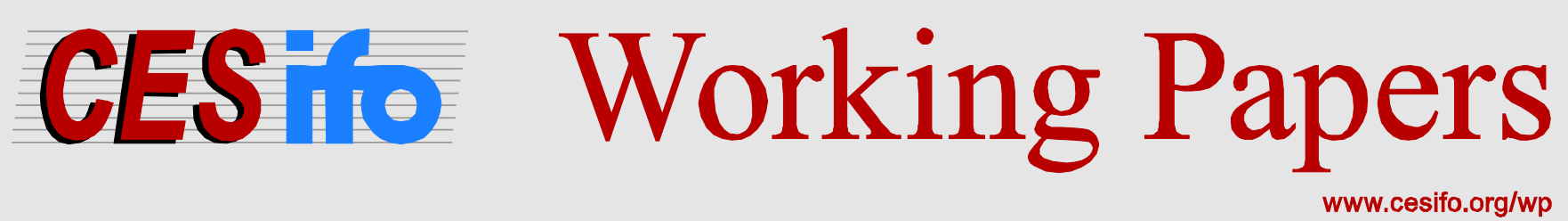

\title{
Advance-Purchase Financing of Projects with Few Buyers
}

\author{
Marco Sahm
}

CESIFO WORKING PAPER NO. 5560

CATEGORY 11: INDUSTRIAL ORGANISATION

ORIGINAL VERSION: OCTOBER 2015

THIS VERSION: OCTOBER 2016

An electronic version of the paper may be downloaded

- from the SSRN website:

- from the RePEc website:

- from the CESifo website:

wWw.SSRN.com

Www.RePEc.org

www.CESifo-group.org/wp 


\title{
Advance-Purchase Financing of Projects with Few Buyers
}

\begin{abstract}
I investigate a simple model of advance-purchase contracts as a mode of financing costly projects. An entrepreneur has to meet some capital requirement in order to start production and sell the related good to a limited number of potential buyers who are privately informed about their willingness to pay. I find that advance-purchase arrangements enable more costly projects to be financed than traditional funding sources. The entrepreneur uses advance-purchase surcharges as a price discrimination device. However, the discriminatory power is limited by the problem of free-riding, which is exacerbated as the number of potential buyers increases.
\end{abstract}

JEL-Code: D420, G320, H410, L120, L260, O310.

Keywords: pre-ordering, price discrimination, excludable public goods, monopolistic provision, crowdfunding, innovation and R\&D.

\author{
Marco Sahm \\ University of Bamberg \\ Feldkirchenstraße 21 \\ Germany - 96045 Bamberg \\ marco.sahm@uni-bamberg.de
}

This version: October 13, 2016

I would like to thank Paul Belleflamme, Thomas Lambert, and Armin Schwienbacher for their inspiring discussions about the basic idea of this article. Moreover, I am very grateful for the insightful comments and helpful suggestions given by Matthew Ellman, Sjaak Hurkens, Martin Peitz, Markus Reisinger, David Zvilichovsky, and many participants of the economics workshops at LMU Munich, TU Munich, and the University of Bayreuth, as well as the following conferences: CESifo Area Conference on Public Sector Economics 2014 (Munich), NoeG 2014 (Vienna), IIPF 2014 (Lugano), CESifo Area Conference on Applied Microeconomics 2015 (Munich), PET 2015 (Luxembourg), EEA 2015 (Mannheim), EARIE 2015 (Munich), and VfS 2015 (Muenster). 


\section{Introduction}

There is a lively political debate in the public health sector about how the research and development $(\mathrm{R} \& \mathrm{D})$ of new drugs and vaccines by private firms can be incentivized properly and how the resulting pharmaceuticals can also be made available in low-income countries. One proposal that would address both problems simultaneously, is the use of advance-purchase arrangements: ${ }^{1}$ Negotiating with the producer, some national or supra-national health authorities may undertake to pre-order a drug and pay in advance (or promise to pay the prespecified price on delivery). Resolving the producer's uncertainty about how countries value the drug, the firm can then use these (promises of) advance payments to finance its R\&D investments. Moreover, poorer countries could benefit from lower prices once the development of the drug has been financed by pre-orders placed by richer countries.

Despite being intuitively appealing, the proposal has not yet undergone a rigorous analysis based on a theoretical economic model. Is it really possible to finance more (costly) R\&D activities based on advance-purchase contracts than relying on traditional funding like debt or equity? Does the use of advance-purchase financing instead of traditional funding actually improve the availability of pharmaceuticals in low-income countries? (Under which circumstances) does advance-purchase financing Pareto-dominate traditional funding?

In this article, I examine these questions employing a simple model of advance-purchase financing. I consider an entrepreneur who must meet a certain capital requirement in order to start production. Once the fixed costs are covered, the entrepreneur has monopoly power and sells the related product to a limited number of potential buyers. Customers are privately informed about their willingness to pay, and buy either one or zero units of the good. Notice that the setup can easily be reinterpreted as a model of the monopolistic provision of excludable public goods under private information. Within this framework, I compare the allocations resulting from two different funding mechanisms: Under traditional (debt or equity) financing, the entrepreneur relies on standard uniform monopoly pricing, whereas advance-purchase financing can be modeled as a two-stage game. In the first stage, the entrepreneur offers to pre-order the good at a certain advancepurchase price. If the money collected from pre-orders fails to cover the fixed

\footnotetext{
${ }^{1}$ Berndt and Hurvitz (2005) provide a comprehensive discussion of this proposal focusing on practical issues. Berndt et al. (2007) estimate the costs and effectiveness of such advance-purchase arrangements. Dalberg (2013) evaluates the process and design of the advance market commitment for pneumococcal vaccines which was organized as a pilot project by Gavi and engaged the manufacturers GlaxoSmithKline and Pfizer.
} 
cost, then the advance purchasers will be reimbursed. If the money collected suffices, the game will move on to the second stage at which the good is produced, delivered to advance-purchasers, and offered to residual customers at a (possibly different) regular price.

In an extension of this baseline model I allow also for mixed financing, i.e. I consider the entrepreneur's possibility to supplement revenues from advance-purchases by traditional funds for meeting the capital requirement whenever the project is profitable from an ex interim perspective.

It transpires that the process of advance-purchase financing enables the entrepreneur to discriminate between customers with different valuations: Agents with a high willingness to pay prefer to pre-order the good at the advance-purchase price because they fear the nonavailability of the product most and consider that their pre-order could be pivotal for its realization. In contrast, agents with a lower valuation prefer to wait, and perhaps purchase the good later at the regular price. This results in an advance-purchase surcharge, i.e. the entrepreneur optimally sets an advance-purchase price above the regular price. Note that the discriminatory power of the entrepreneur rests upon the threat of the potential nonavailability of the product, i.e. on the positive probability that the pre-order of a single agent may be pivotal. Because this probability decreases as the number of potential buyers increases, the problem that agents tend to free-ride on the advance payments of others limits the discriminatory power. Hence, the differential between the advance-purchase price and the regular price declines as the number of potential buyers increases and vanishes in the limit.

Comparing traditional funding and advance-purchase financing, I derive the following results: First, if fixed costs are sufficiently large, the entrepreneur will always prefer advance-purchase financing over traditional funding. Under traditional funding, projects will be realized if and only if they are ex ante profitable. However, ex post, they may turn out to be lossmaking. By contrast, advance-purchase financing enables the entrepreneur to screen and run only projects that are ex post profitable. If the fixed costs that may be avoided this way are sufficiently large, these expected savings will outweigh the disadvantage that it will not be possible to realize all profitable projects under advance-purchase financing due to the problem of free-riding. Second, as this reasoning implies, under advance-purchase financing more costly projects can indeed be realized than under traditional funding. If the fixed costs exceed a certain threshold, projects will not be ex ante profitable and, hence, will definitely not be realized under traditional funding, whereas the probability of being ex post profitable and therefore realized under advance-purchase financing is strictly positive. Third, this shows that advance-purchase financing will actually Pareto-dominate tradi- 
tional funding if fixed costs are sufficiently large.

Qualitatively, all the results also apply to an extension of the model with mixed financing in which the entrepreneur cannot commit to rely exclusively on revenues from advance-purchases for meeting the capital requirement but may supplement them by traditional funds whenever the project is profitable from an ex interim perspective.

Besides the introductory example from health economics, the model captures a series of stylized facts that are characteristic for many markets in which a single seller with increasing returns to scale deals with a limited number of potential buyers. Examples include the international defense industry where an arms manufacturer does business with a limited set of countries, and the international airline industry where a producer of jet engines can virtually only sell to two aircraft companies. The model may also be understood as a simple crowdfunding mechanism for which the financing threshold equals the (residual) capital requirement and the fixed advance payment is rewarded by delivery of the respective product (Belleflamme et al., 2014, cf. ).

The remainder of this article is organized as follows: In Section 2, I review the related literature. Section 3 presents the formal model. In Section 4, I derive the basic properties of the optimal advance-purchase contract and compare it to optimal pricing based on traditional funding. Section 5 illustrates the results for the examples of only one or two potential buyers with uniformly distributed valuations. Section 6 extends the analysis to some limitation of the entrepreneur's commitment opportunities which provokes a mix of advance-purchase financing and traditional funding. In Section 7, I summarize and discuss the main findings.

\section{Related Literature}

In addition to its application to the field of $\mathrm{R} \& \mathrm{D}$ in international health economics (Berndt and Hurvitz, 2005, Berndt et al., 2007), this article is closely related to three further strands of the economic literature.

First, it contributes to a series of articles that analyze the role of advancepurchase contracts as a means of price discrimination. Considering markets with a continuum of potential buyers, the vast majority of seminal articles on this topic find advance-purchase discounts to characterize the optimal pricing scheme. ${ }^{2}$ The optimality of advance-purchase discounts may be due to limited production capacities and uncertainty about the aggregate level of

\footnotetext{
${ }^{2}$ In order to mention some of the few exceptions, advance-purchase surcharges may be optimal if the entrepreneur is capacity-constrained and consumers differ in their likelihood of regretting pre-orders (Nasiry and Popescu, 2012), or if consumers differ in their experience with the good (Zeng, 2013).
} 
demand (Dana, 1998, 1999, 2001, Gale and Holmes, 1992, 1993); it may also be due to different expected valuations among consumers (Nocke et al., 2011, Möller and Watanabe, 2010). Because in a continuum economy no single pre-order is pivotal for the availability of the respective product, in this part of the literature advance-purchase contracts are irrelevant for the financing decision; they are solely an instrument of price discrimination. By contrast, taking into account the strategic effects between a finite number of agents, the optimal advance-purchase contract in my model reflects the entrepreneur's simultaneous financing and pricing decision, yielding an advance-purchase surcharge. ${ }^{3}$ Though the mechanism is different, the intuition for the advancepurchase surcharge is similar to the one for a decreasing price path in the case of clearance sales where consumers with high valuations buy early at high prices because they fear later rationing at low prices (Xie and Shugan, 2001, Nocke and Peitz, 2007, Möller and Watanabe, 2010).

The joint addressing of the financing and pricing decision is a feature that also relates my model to the recent literature on crowdfunding. Belleflamme et al. (2014) and Sahm et al. (2014) derive a similar result considering a crowdfunding model with a continuum of potential consumers. In their framework, however, the optimality of an advance-purchase surcharge originates from the behavioral assumption that consumers who pre-order experience community benefits, i.e. derive additional utility from belonging to the funding crowd. Independently from my own work, two recent working papers on crowdfunding also discuss the optimality of advance-purchase surcharges based on arguments of pivotality (Ellman and Hurkens, 2016, Kumar et al., 2016). In contrast to my study, however, both articles assume that the entrepreneur can commit to some arbitrary funding threshold (possibly differing from the capital requirement), which obviously strengthens his discriminatory power. Consistent with my analysis, Ellman and Hurkens (2016) consider a finite set of potential buyers, but include only two possible valuations. This two-type-model enables them to specify the optimal crowdfunding mechanism which potentially implies multiple advance-purchase prices. By contrast, I focus on a simple mechanism with a single advance-purchase price which allows me to examine a continuum of valuations. Unlike me and them, Kumar et al. (2016) consider a continuum of potential buyers and introduce some ad-hoc notion of pivotality which is not derived from limit considerations in some finite economy. ${ }^{4}$ Other than the aforementioned

\footnotetext{
${ }^{3}$ In a model of bilateral contracting with one principal and a finite number of agents, Segal (2003) discusses the impact of externalities between agents more generally.

${ }^{4}$ Thus their findings conflict with the result that, in a large economy with a continuum of potential buyers, the behavioral assumption of community benefits is critical for crowdfunding to be more profitable than traditional funding (Belleflamme et al., 2014, Sahm
} 
contributions, Strausz (2015) abstracts from issues of price discrimination and focuses on the trade-off between profitable screening and entrepreneurial moral hazard instead of the one between screening and free-riding by consumers in my model. In line with my results, he finds that advance purchase arrangements improve the entrepreneur's investment decision compared to traditional funding schemes.

Finally, as the advance payments from pre-orders can be understood as contributions to the realization and nonrival availability of the product, this article also contributes to the literature on the monopolistic provision of excludable public goods under private information. Early work in this field focused on simple pricing mechanisms that put empirically motivated constraints on the class of admissible contracts (Brito and Oakland, 1980). The more recent contributions usually apply a general mechanism design approach in order to specify optimal contracts (Cornelli, 1996, Schmitz, 1997). Though illustrating that the threat of nonproduction may be a useful instrument of price discrimination between customers with different valuations, these optimal contracts are hardly ever used in practice for two reasons. First, as they are often found to be rather complex, the use of much simpler contracts prevails. ${ }^{5}$ Second, their optimality is based on the assumption that the monopolist can commit not to renegotiate with customers once they have been excluded. Although this may be a reasonable assumption for some instances, it seems to be violated for the introductory examples. In order to deviate from this assumption in the easiest way, I restrict my analysis to simple advance-purchase contracts with posted prices.

\section{Analysis}

In this section, I introduce the basic assumptions, review traditional funding as a benchmark, and model advance-purchase financing as a sequential game. While advance-purchase financing and traditional funding are mutually exclusive in the baseline model, Section 6 extends the analysis allowing for mixed financing.

\subsection{Basic assumptions}

A monopolistic entrepreneur seeks to finance a costly project with a commonly known capital requirement $K$. If the capital requirement is met, the

et al., 2014).

${ }^{5}$ Schmitz (1997) and Norman (2004) show that the monopolist will indeed find it optimal to rely on simple contracts (such as average cost pricing) if the number of potential buyers becomes very large. 
entrepreneur will run the project and produce a related good of a fixed quality normalized to 1. Marginal costs of production are assumed to be zero.

There are $N \in \mathbb{N}$ potential buyers. Depending on their willingness to pay, each potential buyer purchases either zero or one unit of the good. The willingness to pay of buyer $i \in\{1, \ldots, N\}$ is his private information, denoted $\theta_{i}$. It is the realization of a random variable with some commonly known distribution. For the sake of concreteness, assume that all $N$ random variables are independent and identically distributed on $[0,1]$ according to the cumulative distribution function $F$ with some continuously differentiable density $f$. Moreover, I impose the following regularity condition as in Myerson (1981). ${ }^{6}$

Definition $1 F$ will be called regular if function $v$ with $v(\theta):=\theta-\frac{1-F(\theta)}{f(\theta)}$ strictly increases in $\theta$.

If customer $i$ buys one unit of the product at price $p$, he will realize the surplus $U_{i}=\theta_{i}-p$. The surplus from not buying is zero. ${ }^{7}$

The entrepreneur can choose between two mutually exclusive funding mechanisms: either traditional (debt or equity) financing (with opportunity costs of capital normalized to 0) or financing based on advance-purchase commitments. The latter refers to the case in which some customers preorder the product and pay in advance. The advance payments are used to meet capital requirement $K$ and realize the project.

I assume that the entrepreneur has the bargaining power to make take-itor-leave-it price offers. This is common practice in the analysis of monopolies, and leads to a tractable screening model with the uninformed party proposing the contract. If the number of potential buyers is small, however, this assumption is debatable and will be discussed in more detail below.

\subsection{Traditional funding}

As a benchmark, consider the standard model of monopoly pricing in which the entrepreneur cannot commit to not running ex ante profitable projects. ${ }^{8}$ With traditional funding and asymmetric information about customers' preferences, the entrepreneur then relies on uniform pricing in order to maximize expected profits. Once the project is realized, the probability that a certain customer buys at price $p$ is $1-F(p)$. Hence, expected profits equal

$$
E\left(\pi_{0}\right)=N[1-F(p)] p-K .
$$

\footnotetext{
${ }^{6}$ Examples of regularity include uniform, normal, and exponential distributions.

${ }^{7}$ The assumption of risk-neutral customers is particularly appropriate for B2B markets such as those in the introductory examples.

${ }^{8}$ Cornelli (1996) characterizes optimal selling procedures in a model with commitment.
} 
The necessary condition for an optimal price $p_{0}$ does not depend on $K$ and implies $v\left(p_{0}\right)=0$. For any regular $F$, the condition is also sufficient. Accordingly, with traditional funding, the entrepreneur will realize the project if and only if the capital requirement does not exceed the threshold $K_{0}:=N\left[1-F\left(p_{0}\right)\right] p_{0}<N$.

\subsection{Advance-purchase financing}

Project funding based on advance-purchase commitments can be described as a sequential game $\Gamma$ with two stages: In the first stage, the entrepreneur offers all potential buyers the possibility to pre-order the product at price $p_{c}$ and pay in advance. Individuals then simultaneously decide whether to pre-order at this price. If the money collected from pre-orders falls short of capital requirement $K$, advance payments are returned and the game ends. If instead capital requirement $K$ is met, the project is realized and the game moves to the second stage. In the second stage, the entrepreneur sets the regular price $p_{r}$ for buyers who did not pre-order. These residual customers then decide simultaneously whether to buy at this price. I normalize the discount rate to zero so all pay-offs can be treated as if they accrued at the end of stage 2 .

The structure of the game reflects the implicit assumptions about the entrepreneur's bargaining power. Though being able to make take-it-or-leave-it price offers, it is limited in two ways. First, I assume that an advancepurchase contract specifies only the advance-purchase price $p_{c}$. In particular, the minimum number of pre-orders required to run the project cannot be contracted upon explicitly. Put differently, the funding threshold may not differ from capital requirement $K$. The idea is that the entrepreneur may not decide against running the project if the money collected from pre-orders meets the capital requirement, because then the expected profits from realizing the project are positive. ${ }^{9}$ Second, the above timing corresponds to the implicit assumption that the entrepreneur cannot commit to a regular price $p_{r}$ ex ante. This lack of commitment is due to a problem of time-inconsistency similar to that for durable goods: as long as the market is not covered entirely by pre-orderers in stage 1, the entrepreneur always has an incentive to adjust the price in stage 2 in order to address additional buyers and make additional profits. ${ }^{10}$

\footnotetext{
${ }^{9}$ In contrast to this simple contract specifying a single advance-purchase price, Ellman and Hurkens (2016) consider general crowdfunding mechanisms consisting of an arbitrary funding threshold and a set of advance-purchase prices.

${ }^{10}$ By contrast, Cornelli (1996) specifies the optimal general advance-purchase contract for the case in which the entrepreneur can commit to deliver the product only to pre-
} 
In what follows, I solve the game by backward induction for its subgameperfect equilibrium (SPE).

\section{Stage 2}

For any given $p_{c}$, denote by $\Omega_{c} \subset[0,1]$ the set of pre-ordering types, i.e. $\theta_{i} \in$ $\Omega_{c}$ implies that individual $i \in\{1, \ldots, N\}$ pre-orders at price $p_{c}$ in stage 1 . Let $n_{c}<N$ denote the actual realized number of pre-orders, i.e. $n_{c}=\mid\left\{\theta_{i} \in\right.$ $\left.\Omega_{c} \mid i \in\{1, \ldots, N\}\right\} \mid$. Whenever the capital requirement is met, i.e. $n_{c} p_{c} \geq K$, the entrepreneur maximizes his additional conditional expected profits from stage 2

$$
E\left(\pi_{2 n d} \mid n_{c}, \Omega_{c}\right)=\left(N-n_{c}\right) \cdot \operatorname{Prob}\left(\theta \geq p_{r} \mid \theta \notin \Omega_{c}\right) \cdot p_{r}
$$

by the choice of $p_{r}$. Obviously, for any conceivable $\Omega_{c} \subset[0,1]$, the maximizing regular price $p_{r}$ is independent from the realized number of pre-orders $n_{c}$.

As a consequence the set of rational pre-ordering types $\Omega_{c}$ will have a simple structure: any buyer who pre-orders must have a higher willingness to pay for the good than any regular customer.

Lemma 1 For any given prices $p_{c}$ and $p_{r}$ there is some $\theta_{c} \in \mathbb{R} \bigcup\{ \pm \infty\}$ such that customer $i \in\{1, \ldots, N\}$ will pre-order the product if and only if $\theta_{i} \geq \theta_{c}$.

Proof. Denote by $m_{c} \in\{1, \ldots, N\}$ the minimum number of pre-orders required to finance the project for the given advance-purchase price $p_{c}$, i.e. $m_{c} p_{c} \geq K>\left(m_{c}-1\right) p_{c}$. Let $\sigma(m)$ be the probability that the number of pre-orders among $N-1$ potential buyers will be at least $m \in \mathbb{N}$. Trivially, $\sigma(m-1) \geq \sigma(m)$. Some customer with willingness to pay $\theta$ will weakly prefer to pre-order the product if and only if his expected utility from an advancepurchase, $\sigma\left(m_{c}-1\right)\left(\theta-p_{c}\right)$, is at least as high as that from a regular purchase, $\sigma\left(m_{c}\right)\left(\theta-p_{r}\right)$, i.e. if and only if

$$
\left(\sigma\left(m_{c}-1\right)-\sigma\left(m_{c}\right)\right) \theta \geq \sigma\left(m_{c}-1\right) p_{c}-\sigma\left(m_{c}\right) p_{r} .
$$

For $\sigma\left(m_{c}-1\right)=\sigma\left(m_{c}\right)$, nobody (everybody) will pre-order if $p_{c}>p_{r}\left(p_{c} \leq\right.$ $\left.p_{r}\right)$, and $\theta_{c}:=\infty\left(\theta_{c}:=-\infty\right)$ has the stated property. For $\sigma\left(m_{c}-1\right)>\sigma\left(m_{c}\right)$, set $\theta_{c}:=\frac{\sigma\left(m_{c}-1\right) p_{c}-\sigma\left(m_{c}\right) p_{r}}{\sigma\left(m_{c}-1\right)-\sigma\left(m_{c}\right)}$.

Of course, only the non-trivial cases for which $\theta_{c} \in(0,1)$ are of further interest. I refer to $\theta_{c}$ as the threshold valuation because it expresses the

orderers. 
willingness to pay of any buyer who is indifferent to whether or not he preorders. Then, the residual potential buyers in stage 2 are those for which $\theta \in\left[0, \theta_{c}\right)$. Because they actually purchase the good at price $p_{r}$ if and only if $\theta-p_{r} \geq 0$, the conditional probability that such a customer will actually buy in stage 2 equals

$$
\operatorname{Prob}\left(\theta \geq p_{r} \mid \theta \leq \theta_{c}\right)=\frac{\operatorname{Prob}\left(p_{r} \leq \theta \leq \theta_{c}\right)}{\operatorname{Prob}\left(\theta \leq \theta_{c}\right)}=\frac{F\left(\theta_{c}\right)-F\left(p_{r}\right)}{F\left(\theta_{c}\right)} .
$$

Rewriting (2), the entrepreneur maximizes his additional conditional expected profits from stage 2

$$
E\left(\pi_{2 n d} \mid n_{c}\right)=\left(N-n_{c}\right) \cdot \frac{F\left(\theta_{c}\right)-F\left(p_{r}\right)}{F\left(\theta_{c}\right)} \cdot p_{r}
$$

by the choice of $p_{r}$.

Lemma 2 Any optimal regular price satisfies $p_{r}<\theta_{c}$.

Proof. Any $p_{r} \geq \theta_{c}$ would imply $E\left(\pi_{2 n d} \mid n_{c}\right) \leq 0$.

The first-order condition for an optimal solution implies

$$
p_{r}-\frac{F\left(\theta_{c}\right)-F\left(p_{r}\right)}{f\left(p_{r}\right)}=0 .
$$

For any regular $F$, the condition is also sufficient. To see this, note that

$$
v_{\theta_{c}}(\theta):=\theta-\frac{F\left(\theta_{c}\right)-F(\theta)}{f(\theta)}
$$

strictly increases for all $\theta \in\left[0, \theta_{c}\right)$ because

$$
v_{\theta_{c}}^{\prime}(\theta)=2+\frac{\left[F\left(\theta_{c}\right)-F(\theta)\right] f^{\prime}(\theta)}{[f(\theta)]^{2}}>0
$$

This is obvious for $f^{\prime}(\theta) \geq 0$; for $f^{\prime}(\theta)<0$ it follows from the fact that $v$ strictly increases in $\theta$ and thus

$$
v_{\theta_{c}}^{\prime}(\theta)=2+\frac{\left[F\left(\theta_{c}\right)-F(\theta)\right] f^{\prime}(\theta)}{[f(\theta)]^{2}}>2+\frac{[1-F(\theta)] f^{\prime}(\theta)}{[f(\theta)]^{2}}=v^{\prime}(\theta)>0 .
$$

As a regular prize materializes only for $n_{c}<N$, for $n_{c}=N$ define a hypothetical regular prize $p_{r}$ as the unique solution of equation (5). 


\section{Stage 1}

By setting the advance-purchase price, the entrepreneur implicitly determines the threshold valuation as well as the minimum number of pre-orders required to finance the project. To see this, let $p_{n}$ be the advance-purchase price. Then, $n \in\{1, \ldots, N\}$ with

$$
n p_{n} \geq K>(n-1) p_{n}
$$

is the corresponding minimum number of pre-orders required. By definition, for any customer with threshold valuation $\theta_{n}$, the expected payoff from advance-purchase

$$
A(n):=\left[\sum_{i=0}^{N-n}\left(\begin{array}{c}
N-1 \\
n-1+i
\end{array}\right)\left[1-F\left(\theta_{n}\right)\right]^{n-1+i}\left[F\left(\theta_{n}\right)\right]^{N-n-i}\right]\left(\theta_{n}-p_{n}\right)
$$

equals the expected payoff from regular purchase

$$
R(n):=\left[\sum_{i=1}^{N-n}\left(\begin{array}{c}
N-1 \\
n-1+i
\end{array}\right)\left[1-F\left(\theta_{n}\right)\right]^{n-1+i}\left[F\left(\theta_{n}\right)\right]^{N-n-i}\right]\left(\theta_{n}-p_{r}\right) .
$$

Note that the probability that the project will be realized if the customer pre-orders in (7) and the probability that the project will be realized if he does not pre-order in (8) differ only by the probability that his own pre-order will be pivotal for meeting the capital requirement

$$
P(n):=\left(\begin{array}{c}
N-1 \\
n-1
\end{array}\right)\left[1-F\left(\theta_{n}\right)\right]^{n-1}\left[F\left(\theta_{n}\right)\right]^{N-n} .
$$

The equality of (7) and (8) characterizes the relation between the threshold valuation $\theta_{n}$ and the advance-purchase price

$$
p_{n}=\frac{P(n) \theta_{n}+\left[\sum_{i=1}^{N-n}\left(\begin{array}{c}
N-1 \\
n-1+i
\end{array}\right)\left[1-F\left(\theta_{n}\right)\right]^{n-1+i}\left[F\left(\theta_{n}\right)\right]^{N-n-i}\right] p_{r}}{\sum_{i=0}^{N-n}\left(\begin{array}{c}
N-1 \\
n-1+i
\end{array}\right)\left[1-F\left(\theta_{n}\right)\right]^{n-1+i}\left[F\left(\theta_{n}\right)\right]^{N-n-i}}
$$

where $p_{r}$ is implicitly defined by (5) with $\theta_{c}=\theta_{n}$.

Now suppose that $n \in\{1, \ldots, N\}$ is the minimum number of pre-orders required. If the realized number of pre-orders is $i \in\{0, \ldots, N\}$, the entrepreneur's profit will be 0 for $i<n$ and $i p_{n}-K+E\left(\pi_{2 n d} \mid i\right)$ for $i \geq n$. 
Applying (4), the entrepreneur's expected profit $E\left(\pi_{n}\right)$ equals

$$
\sum_{i=n}^{N}\left(\begin{array}{c}
N \\
i
\end{array}\right)\left[1-F\left(\theta_{n}\right)\right]^{i}\left[F\left(\theta_{n}\right)\right]^{N-i}\left[i p_{n}-K+(N-i) \frac{F\left(\theta_{n}\right)-F\left(p_{r}\right)}{F\left(\theta_{n}\right)} p_{r}\right] \text {, }
$$

where $p_{n}$ is given by (10) and $p_{r}$ is implicitly defined by (5) with $\theta_{c}=\theta_{n}$. The problem of finding the advance-purchase price $p_{c}$ that maximizes expected overall profits can therefore be solved in two steps:

Step 1: For any $n \in\{1, \ldots, N\}$ choose the threshold valuation $\theta_{n}$ that maximizes expected overall profits $E\left(\pi_{n}\right)$ given by (11) subject to the constraints (6) and (10), i.e. such that $n$ is indeed the minimum number of preorders required to finance the project for the corresponding advance-purchase price $p_{n}$.

Step 2: Choose $p_{c}:=p_{n^{*}}$ (or equivalently $\theta_{c}:=\theta_{n^{*}}$ ) with $n^{*} \in$ $\arg \max _{n \in\{1, \ldots, N\}} E\left(\pi_{n}\right)$.

\section{Results}

Before taking these steps in order to solve the entrepreneur's problem explicitly for some simple examples in Section 5, I record the general properties of the optimal pricing scheme under advance-purchase financing and compare the respective allocation with the allocation under optimal pricing based on traditional funding.

\subsection{Equilibrium properties of the advance-purchase contract}

Proposition 1 Any SPE of game $\Gamma$ with $N \in \mathbb{N}$ potential buyers and a regular distribution of valuations $F$ has the following properties.

(a) $p_{c}>p_{r}$, i.e. the advance-purchase price exceeds the regular price.

(b) If $n^{*}=N$, then $p_{c}=\theta_{c}$ else $p_{c}<\theta_{c}$, i.e. the advance-purchase price falls short of the threshold valuation unless it is optimal to realize the project only if all potential buyers pre-order.

Proof. As demonstrated in the previous section, there is some $n^{*} \in$ $\arg \max _{n \in\{1, \ldots, N\}} E\left(\pi_{n}\right)$ such that $p_{c}=p_{n^{*}}$ and $\theta_{c}=\theta_{n^{*}}$.

(a) Suppose to the contrary that $p_{c}=p_{n^{*}} \leq p_{r}$. Then the equality of (7) 
and (8) implies

$$
\begin{aligned}
& A\left(n^{*}\right)=\left[\sum_{i=0}^{N-n^{*}}\left(\begin{array}{c}
N-1 \\
n^{*}-1+i
\end{array}\right)\left[1-F\left(\theta_{n^{*}}\right)\right]^{n^{*}-1+i}\left[F\left(\theta_{n^{*}}\right)\right]^{N-n^{*}-i}\right] \\
& \cdot\left(\theta_{n^{*}}-p_{n^{*}}\right) \\
& \geq\left[\sum_{i=0}^{N-n^{*}}\left(\begin{array}{c}
N-1 \\
n^{*}-1+i
\end{array}\right)\left[1-F\left(\theta_{n^{*}}\right)\right]^{n^{*}-1+i}\left[F\left(\theta_{n^{*}}\right)\right]^{N-n^{*}-i}\right] \\
& \cdot\left(\theta_{n^{*}}-p_{r}\right) \\
& =A\left(n^{*}\right)+P\left(n^{*}\right)\left(\theta_{n^{*}}-p_{r}\right),
\end{aligned}
$$

a contradiction as both $P\left(n^{*}\right)$ and $\theta_{n^{*}}-p_{r}$ are positive by equation (9) and Lemma 2, respectively.

(b) If $n^{*}=N$, then the equality of (7) and (8) will imply

$$
0=R(N)=A(N)=\left[1-F\left(\theta_{N}\right)\right]^{N-1}\left(\theta_{N}-p_{N}\right)
$$

and thus $p_{N}=\theta_{N}$; else, by Lemma 2 , it will imply $0<R\left(n^{*}\right)=A\left(n^{*}\right)$ and thus $p_{n^{*}}<\theta_{n^{*}}$.

To get some intuition for these results, note that the product will be available under advance-purchase financing if and only if the entrepreneur collects enough money from pre-orders to run the project. Because agents with a high willingness to pay fear the possible non-availability of the product most, the offered advance-purchase contract serves as a price discrimination device that attracts only customers with the highest valuations. In order to reach additional customers after the project has been realized, the entrepreneur must lower the price and choose $p_{r}<p_{c}$. However, unless all of the $N$ potential buyers have to purchase in advance to meet the capital requirement, any agent's probability of being pivotal for the availability of the product will be smaller than 1. Put differently, from the perspective of any single agent, there is a positive probability that the product will be available later at some reduced price $p_{r}$. The agent's willingness to pay must therefore exceed the advance-purchase price $p_{c}$ by some strictly positive amount for pre-ordering to be attractive to him. The difference $\theta_{c}-p_{c}>0$ can be interpreted as the minimum information rent the entrepreneur has to leave to agents with high valuations in order to make them reveal their willingness to pay. 
Note that any single customer's probability of being pivotal for the availability of the product becomes increasingly small as the number of potential buyers rises. Consequently, the incentives to free-ride on the pre-orders of others increase. The growing problem of free-riding narrows the entrepreneur's possibility to claim a surcharge for pre-orders such that the price differential vanishes in the limit. ${ }^{11}$ With an unbounded customer base, price discrimination by means of advance-purchase surcharges is no longer feasible. $^{12}$

Proposition 2 Consider the SPE of game $\Gamma$ with $N \in \mathbb{N}$ potential buyers, a regular distribution of valuations $F$, and some fixed capital requirement $K$. As the number of potential buyers increases, the difference between the advance-purchase price and the regular price converges to zero, i.e. $\lim _{N \rightarrow \infty} p_{c}-p_{r}=0$.

Proof. For any $N \in \mathbb{N}$ there is some $N^{*} \in \operatorname{argmax}_{n \in\{1, \ldots, N\}} E\left(\pi_{n}\right)$ such that $p_{c}=p_{N^{*}}$ and $\theta_{c}=\theta_{N^{*}}$. Without loss of generality, assume that $\lim _{N \rightarrow \infty} \theta_{N^{*}} \in(0,1)$ if existent; otherwise, either everybody or no one preorders and no discrimination takes place in the limit.

First assume that $N^{*}$ has no upper bound as $N$ increases. In this case, the requirement $\left(N^{*}-1\right) p_{N}^{*}<K$ implies $\lim _{N \rightarrow \infty} p_{N^{*}}=0$ and thus $\lim _{N \rightarrow \infty} p_{N^{*}}-$ $p_{r}=0$ because $0 \leq p_{r} \leq p_{N^{*}}$ for all $N$.

Now suppose that $N^{*}$ is bounded from above by some $\bar{N} \in \mathbb{N}$. The equality of (7) and (8) implies $A\left(N^{*}\right)-R\left(N^{*}\right)=0$, which is equivalent to

$$
p_{N^{*}}-p_{r}=\frac{P\left(N^{*}\right)\left(\theta_{N^{*}}-p_{N^{*}}\right)}{\sum_{i=1}^{N-N^{*}}\left(\begin{array}{c}
N-1 \\
N^{*}-1+i
\end{array}\right)\left[1-F\left(\theta_{N^{*}}\right)\right]^{N^{*}-1+i}\left[F\left(\theta_{N^{*}}\right)\right]^{N-N^{*}-i}} .
$$

The denominator of the fraction on the right-hand side of equation (12) is bounded from below by

$$
\sum_{i=1}^{N-\bar{N}}\left(\begin{array}{c}
N-1 \\
\bar{N}-1+i
\end{array}\right)\left[1-F\left(\theta_{N^{*}}\right)\right]^{\bar{N}-1+i}\left[F\left(\theta_{N^{*}}\right)\right]^{N-\bar{N}-i}>0
$$

\footnotetext{
${ }^{11}$ This limit result resembles the asymptotic considerations by Norman (2004). Nevertheless, Ellman and Hurkens (2016) illustrate that advance purchase financing based on optimal crowdfunding contracts may generate significantly higher surplus than traditional funding even for a considerably large number of potential buyers.

${ }^{12}$ This result is in stark contrast to the findings of Kumar et al. (2016) who base their analysis of a continuum economy on some nonstandard notion of pivotality which is not derived from limit considerations of growing finite economies.
} 
The nominator of the fraction on the right-hand side of equation (12) is bounded from above by

$$
\left(\begin{array}{c}
N-1 \\
(N-1) / 2
\end{array}\right)\left(\frac{1}{2}\right)^{N-1} .
$$

To finish the proof, I show that this last term converges to zero. Substituting $n:=(N-1) / 2$ and applying Stirling's formula $\lim _{n \rightarrow \infty} \frac{n !}{\sqrt{2 \pi n}\left(\frac{n}{e}\right)^{n}}=1$ yields

$$
\begin{aligned}
\lim _{n \rightarrow \infty}\left(\begin{array}{c}
2 n \\
n
\end{array}\right)\left(\frac{1}{2}\right)^{2 n} & =\lim _{n \rightarrow \infty} \frac{(2 n) !}{(n !)^{2} \cdot 4^{n}} \\
& =\lim _{n \rightarrow \infty} \frac{\sqrt{2 \pi 2 n}\left(\frac{2 n}{e}\right)^{2 n}}{\left[\sqrt{2 \pi n}\left(\frac{n}{e}\right)^{n}\right]^{2} \cdot 4^{n}} \\
& =\lim _{n \rightarrow \infty} \frac{1}{\sqrt{\pi n}}=0 .
\end{aligned}
$$

\subsection{Traditional funding vs. advance-purchase financing}

Under traditional funding, only projects with fixed costs $K \leq K_{0}<N$ will be realized. Under advance-purchase financing, in contrast, the probability of realization is positive for all projects with fixed costs $K<N$. Put differently, more costly projects can be realized based on advance-purchase financing than based on traditional funding. Thus, for sufficiently high fixed costs, advance-purchase financing does not only increase the entrepreneur's profit but Pareto dominates traditional funding.

Proposition 3 For any number of potential buyers $N \in \mathbb{N}$, any capital requirement $K \in \mathbb{R}$, and any regular distribution of valuations $F$ the following statements hold:

(a) For any $K \in\left(K_{0}, N\right)$, the project is not realized under traditional funding but has a strictly positive probability of realization under advancepurchase financing.

(b) There is some $K_{1} \in\left[0, K_{0}\right)$ such that the entrepreneur strictly prefers advance-purchase financing over traditional funding if $K \in\left(K_{1}, N\right)$.

(c) There is some $K_{2} \in\left[K_{1}, K_{0}\right]$ such that the allocation under advancepurchase financing Pareto-dominates the allocation under traditional funding if $K \in\left(K_{2}, N\right)$. 
Proof. Consider the entrepreneur's strategy to choose an advance-purchase price $p_{N}$ that makes each potential buyer pivotal for running the project. Obviously, the corresponding expected profit

$$
E\left(\pi_{N}\right)=\left[1-F\left(p_{N}\right)\right]^{N}\left(N p_{N}-K\right)
$$

is a lower bound for the entrepreneur's optimal profit under advance-purchase financing. The optimal $p_{N}$ maximizes (13) subject to the constraints

$$
N p_{N} \geq K>(N-1) p_{N} .
$$

For any regular $F$, the unconstrained solution to this problem can be derived from the first-order condition and is implicitly given by

$$
N p_{N}-\frac{1-F\left(p_{N}\right)}{f\left(p_{N}\right)}=K
$$

As $v\left(p_{N}\right)$ strictly increases in $p_{N}$, so does the left-hand side of this equation, rising from some negative value $-1 / f(0)$ to $N$ as $p_{N}$ increases from 0 to 1 . The equation thus has an interior solution for all $K<N$. This solution will satisfy the first constraint $N p_{N}-K=\frac{1-F\left(p_{N}\right)}{f\left(p_{N}\right)}>0$. Moreover, it will meet the second constraint

$$
K-(N-1) p_{N}=p_{N}+K-N p_{N}=p_{N}-\frac{1-F\left(p_{N}\right)}{f\left(p_{N}\right)}>0
$$

as well if and only if $p_{N}>p_{0}$. In this case, the expected profit equals $E\left(\pi_{N}\right)=$ $\left[1-F\left(p_{N}\right)\right]^{N+1}>0$. Otherwise the entrepreneur can set $p_{N}$ arbitrarily close to $\frac{K}{N-1}<p_{0}<1$. The corresponding expected profit is then given by

$$
E\left(\pi_{N}\right)=\left[1-F\left(\frac{K}{N-1}\right)\right]^{N}\left(\frac{K}{N-1}\right)>0 .
$$

This proves part (a) of the Proposition and implies part (b) as $E\left(\pi_{N}\right)>$ $0=E\left(\pi_{0}\right)$ at $K=K_{0}$. Moreover, it also implies part (c) as the allocation under advance-purchase financing Pareto-dominates the allocation under traditional funding for at least all $K \in\left(K_{0}, N\right)$.

As stated in Proposition 3, advance-purchase financing leads to welfare improvements in at least all those cases in which the capital requirement cannot be met under traditional funding. For sufficiently high capital requirements, advance-purchasing contracts are in the interest of all agents. 
For small capital requirements, however, this is unambiguously true only for customers with valuations below the uniform price $p_{0}$. For all other agents, the incidence of advance-purchase financing is less clear.

Proposition 4 Consider a situation with $N \in \mathbb{N}$ potential buyers, some regular distribution of valuations $F$, and some capital requirement $K \leq K_{0}$. Compared to the allocation under traditional funding, in the allocation under advance-purchase financing

(a) the regular price $p_{r}$ falls short of the uniform price $p_{0}$,

(b) consumers with valuations $\theta \in\left[0, p_{r}\right]$ are equally well-off,

(c) consumers with valuations $\theta \in\left(p_{r}, p_{0}\right)$ are at least as well-off, and strictly better off if $n^{*}<N$.

(d) consumers with valuations $\theta \in\left[\theta_{c}, 1\right]$ will be worse off if $p_{c}>p_{0}$.

Proof.

(a) The first-order condition (5) implies $v\left(p_{r}\right)<0$. Because $v$ strictly increases and $v\left(p_{0}\right)=0$, this implies $p_{r}<p_{0}$.

(b) Because $p_{r}<p_{0}$, consumers with $\theta \in\left[0, p_{r}\right]$ will not buy in either case.

(c) Because $p_{r}<p_{0}$, consumers with $\theta \in\left(p_{r}, p_{0}\right)$ will definitely not buy under traditional funding but may possibly buy under advance-purchase financing and thus derive a positive expected utility unless $n^{*}=N$ and $\theta<\theta_{c}$.

(d) Under advance-purchase financing, consumers with $\theta \in\left[\theta_{c}, 1\right]$ pre-order and will thus possibly buy at a higher price if $p_{c}>p_{0}$. Moreover, they face a positive probability that the product will not be available.

In combination with part (c) of Proposition 3, part (d) of Proposition 4 implies that, whenever $p_{c}>p_{0}$, the allocation under advance-purchase financing Pareto-dominates the allocation under traditional funding if and only if $K \in\left(K_{0}, N\right)$. The example of two potential buyers with uniformly distributed valuations below illustrates, however, that this condition is not always met: in a certain range of fixed costs, the entrepreneur may find it optimal to choose an advance-purchase price $p_{c}$ below the uniform price $p_{0}$.

Whether the remaining consumers with $\theta \in\left[p_{0}, \theta_{c}\right)$ profit from advancepurchase financing is, in general, ambiguous. On the one hand, they have 
to pay less under advance-purchase financing. On the other hand, however, there is a positive probability that the product will not be available, whereas it will be produced for sure under traditional funding. As the examples of the next section will show, the incidence of advance-purchasing contracts on the entrepreneur also depends on the exact capital requirement.

\section{Examples}

In this section I will explicitly solve the game for the examples of one, two, and three potential buyers with uniformly distributed valuations. These cases illustrate the most relevant aspects: The example with only one potential buyer highlights how advance-purchase contracts enable more costly projects to be financed than traditional funding methods. The example with two potential buyers shows how advance-purchase contracts can be used for price discrimination and why this use is limited by free-riding arising from the public goods character of pre-orderers' contributions to the realization of the project. Together with the results from the case of three potential buyers, the examples suggest some further properties of the advance-purchase contract.

Note that with $F(\theta)=\theta$ and $f(\theta)=1$ for all $\theta \in[0,1]$, the optimal uniform price under traditional funding equals $p_{0}=1 / 2$ and the corresponding expected profit equals $E\left(\pi_{0}\right)=N / 4-K$, i.e. projects are realized if and only if $K \leq K_{0}=N / 4$. Moreover, it is easy to compute that the regular price under advance-purchase financing equals $p_{r}=\theta_{c} / 2$ and the corresponding expected profit from additional sales in stage 2 equals $E\left(\pi_{2 n d} \mid n_{c}\right)=\left(N-n_{c}\right) \cdot \theta_{c} / 4$.

\subsection{Example: $N=1$}

I first consider the case with one potential buyer only. With traditional funding, the project can be realized if and only if $K \leq 1 / 4$. In this case, the customer buys the product if and only if he has a willingness to pay of at least $p_{0}=1 / 2$, yielding an expected profit of $E\left(\pi_{0}\right)=1 / 4-K$.

With funding based on an advance-purchase contract, the project is realized if and only if the potential buyer pre-orders at the advance-purchase price $p_{c}$. Accordingly, the entrepreneur maximizes his expected profit

$$
E\left(\pi_{1}\right)=\left(1-p_{c}\right)\left(p_{c}-K\right)
$$

by the choice of $p_{c}$ subject to the constraint that $p_{c} \geq K$. The unconstrained solution to this problem is given by $p_{c}=\frac{1+K}{2}$. It is feasible for all $K \leq 1$.

The expected profits related to the two alternative financing schemes are depicted in Figure 1. A comparison shows that, with funding based on an 


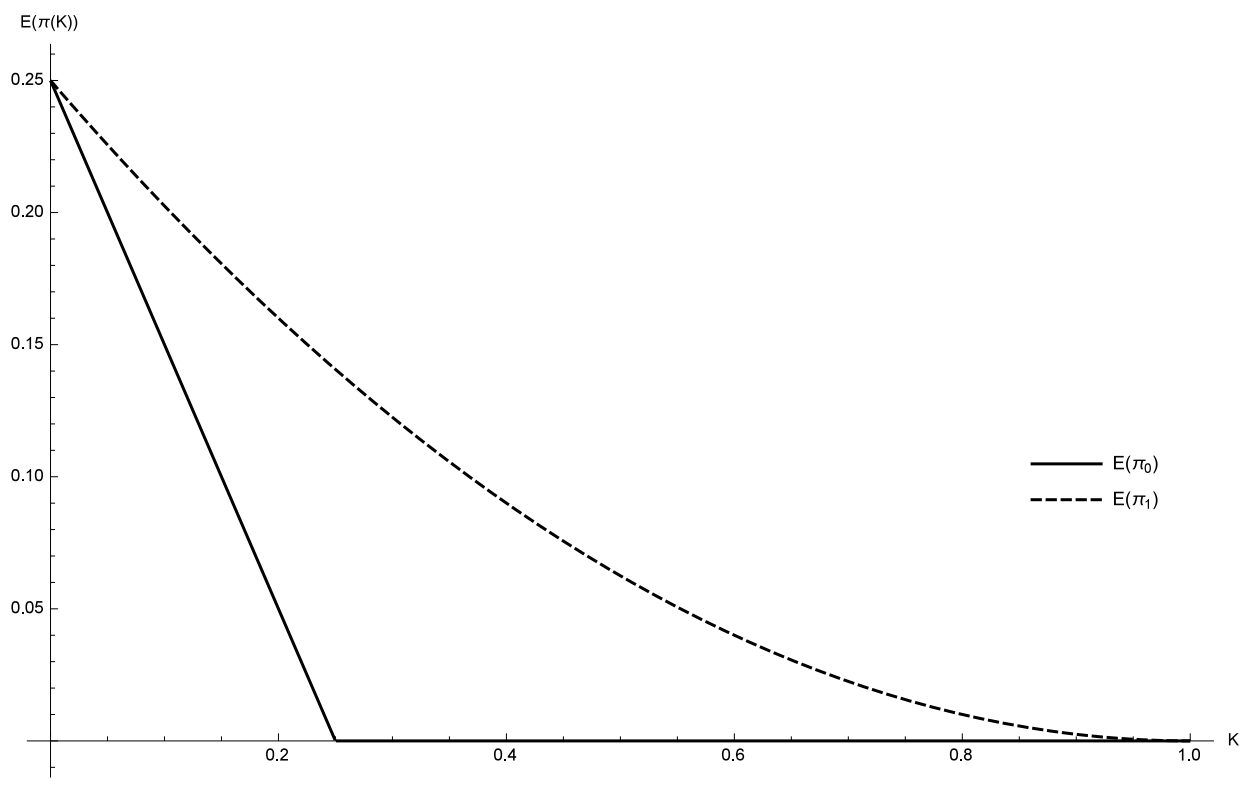

Figure 1: Graphs of $E\left(\pi_{0}\right)$ and $E\left(\pi_{1}\right)$ as functions of $K$

advance-purchase contract, more costly projects can be realized than with traditional funding. Under the requirement of pre-ordering, the entrepreneur will incur the fixed costs only if the purchase actually takes place. This eliminates the possibility of making losses and leads to a stricter policy of exclusion: the entrepreneur raises the advance-purchase price above the monopoly price under traditional funding. Though this decreases the probability of realizing the project and selling the product, the effect of increased profits in case of realization dominates.

For $1 / 4<K<1$, the probability of realization is zero under traditional funding but strictly positive under advance-purchase financing. Hence, the latter Pareto-dominates the former for sufficiently large fixed costs. For $0 \leq$ $K \leq 1 / 4$, however, any type of customer would prefer traditional funding and uniform pricing over financing based on advance-purchase contracts because $p_{c}>p_{0}$. This raises the question whether the entrepreneur can commit to rely exclusively on the latter funding method. If the entrepreneur lacks such commitment power, only projects with $1 / 4<K \leq 1$ can be realized based on advance-purchase contracts, whereas all projects with $0 \leq K \leq 1 / 4$ have to be financed traditionally.

\subsection{Example: $N=2$}

To illustrate the strategic effects among customers, I now consider the case with two potential buyers. With traditional funding, the project can be 
realized if and only if $K \leq 1 / 2$. In this case, some customer buys the product if and only if he has a willingness to pay of at least $p_{0}=1 / 2$, yielding an expected profit of $E\left(\pi_{0}\right)=1 / 2-K$.

To finance the project based on advance-purchase contracts, the entrepreneur can address either one or both potential buyers. Capital requirement $K$ determines which of the two strategies depicted below yields higher expected profits.

First suppose that the entrepreneur sets the advance purchase price to $p_{1}$ relying on at least one pre-order. The customer who is indifferent to whether or not to pre-order is characterized by the threshold valuation $\theta_{1}$ for which the utility from pre-ordering $\theta_{1}-p_{1}$ equals the expected utility from a possible regular purchase $\left(1-\theta_{1}\right)\left(\theta_{1}-p_{r}\right)$. Remember that the regular price is anticipated to equal $p_{r}=\theta_{c} / 2$. Hence, using equation (10), the threshold valuation is characterized by

$$
p_{1}=\theta_{1}\left(1-\frac{1}{2}\left(1-\theta_{1}\right)\right)=\frac{1}{2} \theta_{1}\left(1+\theta_{1}\right)
$$

The entrepreneur's problem can therefore be stated as follows: choose $\theta_{1}$ in order to maximize the expected profit

$$
\begin{aligned}
E\left(\pi_{1}\right) & =\left(1-\theta_{1}\right)^{2} \cdot\left(2 p_{1}-K\right)+2\left(1-\theta_{1}\right) \theta_{1} \cdot\left(p_{1}+\frac{\theta_{1}-p_{r}}{\theta_{1}} p_{r}-K\right) \\
& =-\frac{3}{2} \theta_{1}^{3}+\left(\frac{1}{2}+K\right) \theta_{1}^{2}+\theta_{1}-K
\end{aligned}
$$

subject to the constraint that one pre-order is sufficient to finance the project, i.e. $p_{1}=\frac{1}{2} \theta_{1}\left(1+\theta_{1}\right) \geq K$. The unconstrained solution to this problem is derived from the necessary condition $\partial E\left(\pi_{1}\right) / \partial \theta_{1}=0$, yielding

$$
\theta_{1}=\frac{1}{9}\left(\sqrt{18+(1+2 K)^{2}}+1+2 K\right) \text {. }
$$

It will satisfy the constraint $p_{1} \geq K$ if and only if capital requirement $K$ is below a certain threshold $\tilde{K} \approx 0.76$. Otherwise, the solution is given by $p_{1}=K$ and $\theta_{1}=\sqrt{2 K+1 / 4}-1 / 2$, which is feasible for all $K \leq 1$. The entrepreneur's resulting expected profit from financing the project by at least one pre-order $E\left(\pi_{1}\right)$ is depicted in Figure 2.

Now consider a minimum number of two pre-orders. The project can then be realized if and only if both potential buyers purchase in advance. The entrepreneur's problem can therefore be stated as follows: choose $p_{2}$ in 


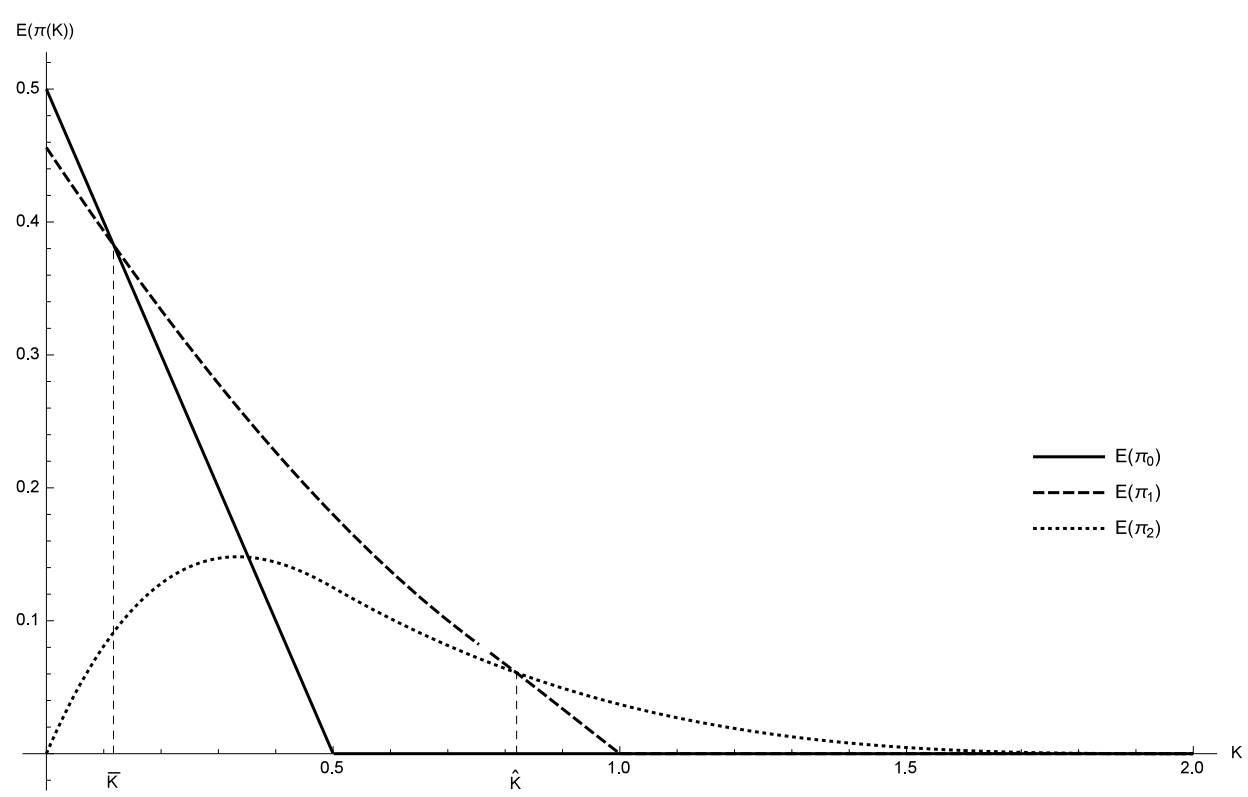

Figure 2: Graphs of $E\left(\pi_{0}\right), E\left(\pi_{1}\right)$, and $E\left(\pi_{2}\right)$ as functions of $K$

order to maximize the expected profit

$$
\begin{aligned}
E\left(\pi_{2}\right) & =\left(1-p_{2}\right)^{2} \cdot\left(2 p_{2}-K\right) \\
& =2 p_{2}^{3}-(4+K) p_{2}^{2}+(2+2 K) p_{2}-K
\end{aligned}
$$

subject to the constraints that two pre-orders are sufficient but one preorder is insufficient to finance the project, i.e. $2 p_{2} \geq K>p_{2}$. The unconstrained solution to this problem is derived from the necessary condition $\partial E\left(\pi_{2}\right) / \partial p_{2}=0$, yielding $p_{2}=(K+1) / 3$. It will satisfy the constraints $2 p_{2} \geq K>p_{2}$ if and only if $1 / 2<K \leq 2$. It then yields the expected profit $E\left(\pi_{2}\right)=\left(\frac{2-K}{3}\right)^{3}$. For $K \leq 1 / 2$, no solution exists unless there is a smallest monetary unit $\mu$. As $\mu \rightarrow 0$, the optimal price $p_{2}$ converges to $K$, yielding the asymptotic expected profit $E\left(\pi_{2}\right)=(1-K)^{2} K$. The entrepreneur's resulting expected profit from financing the project by at least two pre-orders $E\left(\pi_{2}\right)$ is also depicted in Figure 2.

The optimum expected profit from advance-purchase financing is given by the upper envelope of $E\left(\pi_{1}\right)$ and $E\left(\pi_{2}\right)$ as functions of $K$. As Figure 2 illustrates, it will be better to use contracts based on at least one (two) pre-order(s) if capital requirement $K$ is below (above) a certain threshold $\hat{K} \approx 0.82$.

Observe that, with two potential buyers, the use of advance-purchase 
contracts as a device of price discrimination is limited in the following sense. Although advance-purchase financing is still a more profitable measure for sufficiently high fixed costs, the entrepreneur prefers traditional funding for capital requirements $K$ below a certain threshold $\bar{K} \approx 0.11$. The reason for this limitation is a problem of free-riding arising from the public goods character of the customers' advance payments as contributions to the fixed costs. First, if financing is based on at least one pre-order, the agents' probability of being pivotal for the realization of the project will be smaller than one. This induces an advance-purchase price $p_{1}$ below the threshold valuation $\theta_{1}$, i.e. a positive information rent even for the marginal pre-order, and reduces the gap between the advance-purchase price $p_{1}$ and the regular price $p_{r}$. Second, if financing would be based on at least two pre-orders, in the relevant range the advance-purchase price $p_{2}$ would be limited by the incentive compatibility constraint that one single pre-order must not be sufficient to cover the fixed costs. Both effects undermine the discriminatory power of advance-purchase contracts.

Discussing the welfare effects for consumers, note once more that for $1 / 2<K<2$, the probability of realization is zero under traditional funding but strictly positive under advance-purchase financing. Hence, the latter also Pareto-dominates the former in this range of fixed costs. For fixed costs $\bar{K} \leq$ $K \leq 1 / 2$, for which the entrepreneur prefers advance-purchase financing over traditional funding, customers who pre-order, i.e. with valuations $\theta \geq \theta_{c}=\theta_{1}$ as given by equation (18), would actually prefer traditional funding and uniform pricing over financing based on advance-purchase contracts because $p_{c}=p_{1}>1 / 2=p_{0}$ in this range. ${ }^{13}$ Customers who do not pre-order, i.e. with valuations $\theta<\theta_{c}=\theta_{1}$ as given by equation (18), prefer advance-purchase financing over traditional funding if and only if

$$
\left(1-\theta_{c}\right)\left(\theta-p_{r}\right) \geq \theta-p_{0} \quad \Leftrightarrow \quad \theta \leq \bar{\theta}:=\frac{1-\theta_{c}\left(1-\theta_{c}\right)}{2 \theta_{c}} .
$$

Summing up, for $\bar{K} \leq K \leq 1 / 2$, customers with valuations below $\bar{\theta}$ prefer advance-purchase financing, whereas customers with valuations above $\bar{\theta}$ prefer traditional funding. As $\bar{\theta}$ decreases in $\theta_{c}$ and $\theta_{c}=\theta_{1}$ increases in $K$, threshold $\bar{\theta}$ decreases in $K$.

Similar to the case of one potential buyer only, the fact that pre-orderers

\footnotetext{
${ }^{13}$ Notice, however, that $p_{c}=p_{1}<1 / 2=p_{0}$ will be optimal if

$$
\theta_{1}<\frac{\sqrt{5}-1}{2} \Leftrightarrow K<\check{K} \approx 0.08<\bar{K} .
$$
}


prefer traditional funding here again raises the question whether the entrepreneur can commit to rely exclusively on advance-purchase financing. Section 6 discusses this question in detail.

\subsection{Example: $N=3$}

Analog calculations yield similar results for the case with three potential buyers. Just as above, Figure 3 depicts the entrepreneur's respective expected profits forming a related pattern. Again, the optimum expected profit from advance-purchase financing is given by the upper envelope of $E\left(\pi_{1}\right), E\left(\pi_{2}\right)$, and $E\left(\pi_{3}\right)$ as functions of $K$.

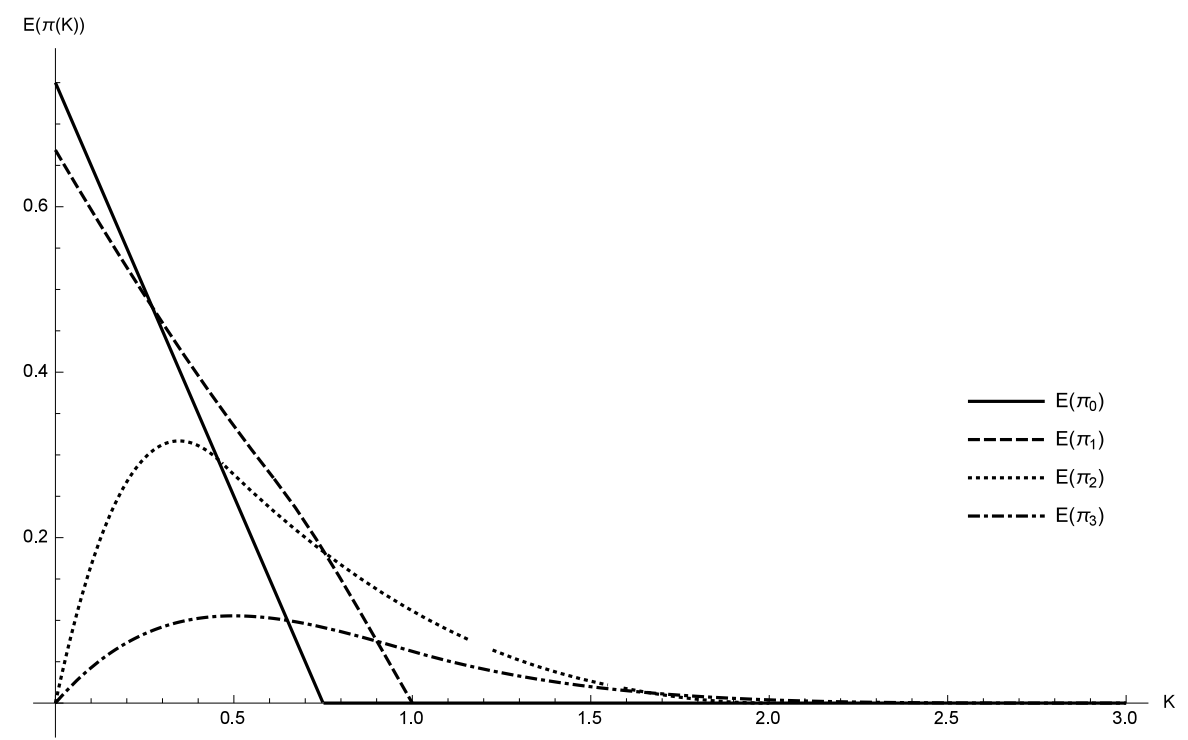

Figure 3: Graphs of $E\left(\pi_{0}\right), E\left(\pi_{1}\right), E\left(\pi_{2}\right)$, and $E\left(\pi_{3}\right)$ as functions of $K$

The examples give rise to the conjecture that the optimal minimum number of required pre-orders $n^{*}$ increases and the expected profit from advancepurchase financing $E\left(\pi_{n}^{*}\right)$ strictly decreases as the capital requirement $K$ increases. Moreover, the examples suggest that Proposition 3 may be tightened in two ways: First, there is some $K_{1} \in\left[0, K_{0}\right)$ such that the entrepreneur strictly prefers advance-purchase financing over traditional funding if and only if $K \in\left(K_{1}, N\right)$. Second, $K_{2}=K_{0}$, i.e. the allocation under advancepurchase financing Pareto-dominates the allocation under traditional funding if and only if $K \in\left(K_{0}, N\right)$. 


\section{Extension}

Assuming that the project will be realized only if the money collected from pre-orders covers the capital requirement entirely, i.e. if $n_{c} p_{c} \geq K$, the previous analysis applies to situations in which the entrepreneur can commit to rely exclusively on advance-purchase financing. Such commitment may be feasible due to credible institutional constraints, e.g. contractual arrangements with third parties such as the use of crowdfunding platforms, or binding credit constraints, e.g. in the case of exhausted traditional funding sources. ${ }^{14}$ The assumption is equivalent to the one of prohibitively high costs of traditional funding. In case of moderate capital costs, however, committing to the exclusive use of revenues from pre-orders may not be possible. In this section I extend the analysis of advance-purchase financing to such instances without commitment.

\subsection{Mixed financing}

No commitment means that, for meeting the capital requirement, the entrepreneur will use traditional funding sources in order to supplement revenues from pre-orders whenever the project is ex interim profitable. Put differently, the project will be realized if and only if the expected profit is positive given the revenues collected from pre-orders. Formally, the present model has to be modified only with respect to the condition under which the project will be realized. In order to specify this condition, I use the previous notation and normalize the capital costs of traditional funding to zero: ${ }^{15}$

$$
n_{c} p_{c}+\left(N-n_{c}\right) \frac{F\left(\theta_{c}\right)-F\left(p_{r}\right)}{F\left(\theta_{c}\right)} p_{r} \geq K
$$

I refer to the respective combination of revenues from pre-orders $n_{c} p_{c}$ and supplementary traditional funds $K-n_{c} p_{c}$ as mixed financing. Notice that mixed financing includes the possibility of using traditional funds only, because the entrepreneur can deliberately induce that no potential buyer preorders by choosing some sufficiently high advance-purchase price. In this respect, mixed financing will be at least as profitable as pure traditional funding. The relevant question is thus whether an entrepreneur, who can-

\footnotetext{
${ }^{14}$ In the latter case, $K$ may be reinterpreted as the capital requirement beyond the debt limit.

${ }^{15}$ The capital costs of traditional funding may be interpreted as a measure of commitment opportunities ranging from 0 (no commitment) to $\infty$ (full commitment). As I will show in this section, the results on advance-purchase financing are qualitatively the same for both extremes. Hence, they presumably apply to the full range.
} 
not commit to rely exclusively on advance-purchase financing, may still earn strictly larger profits by the use of mixed financing instead of pure traditional funding. In other words, is there scope for price discrimination by means of advance-purchase financing even without commitment to its exclusive use?

Basically, the answer to this question is yes. Qualitatively, all previous results on advance-purchase financing remain valid even without commitment to its exclusive use. In the Appendix, I show that analogs to the main Lemmas and Propositions hold for mixed financing, too. Due to the lack of commitment, however, the advantage of mixed financing over pure traditional funding will, in general, arise less frequently and be less pronounced than the advantage of pure advance-purchase financing over pure traditional funding.

In order to get some intuition for these findings, notice that the lack of commitment affects neither the entrepreneur's decision about the regular price $p_{r}$ in stage 2 nor his objective function when he decides about the advance-purchase price $p_{c}$ in stage 1 . It only affects the constraints which determine the minimum number $n$ of pre-orders that is necessary for the project to be realized given a certain advance-purchase price $p_{n}$ : inequalities (6) turn into

$n p_{n}+(N-n) \frac{F\left(\theta_{n}\right)-F\left(p_{r}\right)}{F\left(\theta_{n}\right)} p_{r} \geq K>(n-1) p_{n}+(N-n+1) \frac{F\left(\theta_{n}\right)-F\left(p_{r}\right)}{F\left(\theta_{n}\right)} p_{r}$.

A comparison of (6) and (21) shows that the minimum number of pre-orders $n$ must, ceteris paribus, decrease because the condition of the right inequality tightens. On the one hand, such a decrease of the minimum number of pre-orders $n$ tends to lower profitable revenues from advance-purchases but, on the other hand, will often be possible because the condition of the left inequality loosens. More generally, though the inequalities in (21) mostly imply stricter constraints on feasible combinations of $n, p_{n}$, and $\theta_{n}$ than the inequalities in (6), they are usually not prohibitive for the use of advancepurchase surcharges as a means of price discrimination.

\subsection{Example: $N=2$}

In order to illustrate these results, I reconsider the example from Section 5.2 with $N=2$ potential buyers and uniformly distributed valuations. The entrepreneur's potential strategies can be divided into three categories: he may either rely on zero, one, or two pre-orders.

As shown above, for $K \leq 1 / 2$, he can rely exclusively on traditional funding choosing some prohibitively high advance purchase price and the regular price $p_{0}=1 / 2$. The corresponding expected profit $E\left(\pi_{0}^{m}\right)=1 / 2-K$ 
is depicted in Figure 4.

If the entrepreneur uses mixed financing based on at least one pre-order, revenues from one pre-order plus the expected profit from the potential regular sale must be sufficient, whereas the expected profits from potential regular sales alone must not be sufficient to finance the project. I.e. the entrepreneur's problem of maximizing expected profits (17) is, now, constrained by the conditions

$$
p_{1}+\frac{\theta_{1}}{4} \geq K>2 \cdot \frac{\theta_{1}}{4}
$$

with $0 \leq \theta_{1} \leq 1$ (remember that $p_{r}=\theta_{1} / 2$ ). Using (16), straightforward calculations show that the unconstrained solution (18) will satisfy these conditions if and only if $\frac{1+\sqrt{15}}{14}<K \leq \frac{5}{4}$. For $K>\frac{5}{4}$, the project cannot be financed based on one pre-order. For $K \leq \frac{1+\sqrt{15}}{14}$, no solution exists unless there is a smallest monetary unit $\mu$. As $\mu \rightarrow 0$, the optimal threshold valuation $\theta_{1}$ converges to $2 K$. The entrepreneur's resulting expected profit from mixed financing based on at least one pre-order $E\left(\pi_{1}^{m}\right)$ is also depicted in Figure 4.

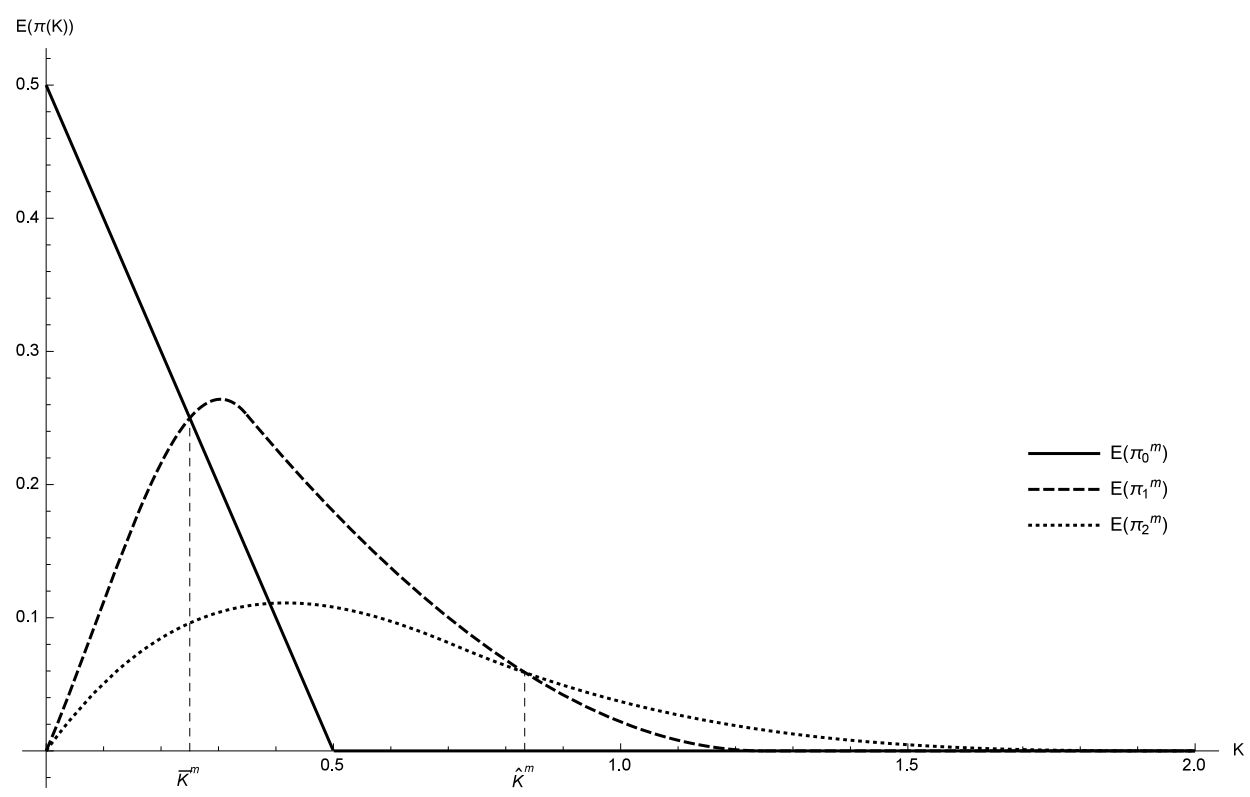

Figure 4: Graphs of $E\left(\pi_{0}^{m}\right), E\left(\pi_{1}^{m}\right)$, and $E\left(\pi_{2}^{m}\right)$ as functions of $K$

Now consider a minimum number of two pre-orders. In this case, revenues from two pre-orders must be sufficient, whereas revenues from one pre-order plus the expected profit from the potential regular sale must not be sufficient to finance the project. Thus the entrepreneur chooses $p_{2}$ in order to maximize 
expected profits (19) subject to

$$
2 p_{2} \geq K>p_{2}+\frac{\theta_{2}}{4}
$$

with $p_{2}=\theta_{2}$. The unconstrained solution $p_{2}=(K+1) / 3$ will satisfy these constraints if and only if $5 / 7<K \leq 2$ yielding the expected profit $E\left(\pi_{2}^{m}\right)=$ $\left(\frac{2-K}{3}\right)^{3}$. For $K \leq 5 / 7$, no solution exists unless there is a smallest monetary unit $\mu$. As $\mu \rightarrow 0$, the optimal price $p_{2}$ converges to $4 K / 5$, yielding the asymptotic expected profit $E\left(\pi_{2}^{m}\right)=\left(1-\frac{4}{5} K\right)^{2} \cdot \frac{3}{5} K$. The entrepreneur's resulting expected profit from mixed financing based on at least two preorders $E\left(\pi_{2}^{m}\right)$ is also depicted in Figure 4.

The optimum expected profit from mixed financing is given by the upper envelope of $E\left(\pi_{0}^{m}\right), E\left(\pi_{1}^{m}\right)$, and $E\left(\pi_{2}^{m}\right)$ as functions of $K$. As Figure 4 illustrates, there are again two thresholds, $\bar{K}^{m}=0.25$ and $\hat{K}^{m} \approx 0.833$ : It will be best to use i) pure traditional funding if capital requirement $K$ is below $\bar{K}^{m}$, ii) mixed financing based on at least one pre-order if it is between $\bar{K}^{m}$ and $\hat{K}^{m}$, and iii) contracts based on at least two pre-orders if it is above $\hat{K}^{m}$.

Comparing mixed financing (Figure 4) with the mutual exclusive use of either traditional funding or advance-purchase financing (Figure 2), three observations are of particular interest. First, $\bar{K}^{m}>\bar{K}$, i.e. for fixed costs $K$ in between these two thresholds, the lack of commitment under mixed financing precludes the profitable use of advance-purchase contracts based on one preorder. Second, the expected profit from mixed financing is not monotonically decreasing in $K$ but locally increasing for revenue requirements just above $\bar{K}^{m}$. To understand this pattern, notice that the lack of commitment is particularly problematic for low fix costs because low fix costs increase the ex interim profitability of traditional funding supplements and thus require low advance-purchase prices to incentivize pre-orders. Third, $\hat{K}^{m}>\hat{K}$, i.e. under mixed financing, the entrepreneur is able to profitably use advance-purchase contracts based on one pre-order for higher fixed costs than with commitment to its exclusive use and, thus, make strictly higher profits for $K \in\left[\tilde{K}, \hat{K}^{m}\right]$. Put differently, even if the entrepreneur has the option to commit to the exclusive use of advance-purchase contracts, he will not always want to use it because mixed financing yields strictly higher profits in some cases. The reason is that, in the respective range of fixed costs, the constraint that one pre-order must be sufficient to finance the project will be binding only if the entrepreneur is committed not to supplement the revenues from advancepurchases by traditional funds. 


\section{Conclusion}

I studied a simple model of advance-purchase financing in which a monopolist has to meet some capital requirement in order to start production. He then sells the related good to a limited number of potential buyers who are privately informed about their willingness to pay. In contrast to most of the previous literature, I have shown that advance-purchase surcharges may arise as an instrument of price discrimination due to the threat of nonproduction. The discriminatory power, though, is limited by the problem of free-riding, which is exacerbated as the number of potential buyers increases.

The setting considered in this article can also be interpreted as a model of the monopolistic provision of excludable public goods under private information. Indeed, the introductory example of $R \& D$ in the public health sector allows for this interpretation. I have shown that advance-purchase arrangements enable more costly projects to be financed than traditional funding sources. ${ }^{16}$ Thus, the former mode of financing will Pareto-dominate the latter if the capital requirement is sufficiently large. Besides efficiency concerns, following the ability-to-pay-principle, advance-purchase financing may also improve on the fairness of the allocation under traditional funding and uniform pricing: If the buyers' different valuations stem from differences in income and if the good under consideration is normal, richer customers will pay the advance-purchase surcharges. In contrast, poorer customers may be able to buy at the regular price below the uniform price under traditional funding. In the context of $R \& D$ in the international health sector, this means that, in many instances, advance purchase contracts could indeed improve the availability of new drugs and vaccines in poorer countries.

The analysis presented here assumes that the bargaining power is on the seller side: though limited by the lack of commitment to not renegotiate with initially excluded customers and the inability to commit to some funding goal above the actual capital requirement, the entrepreneur is able to make take-it-or-leave-it price offers. In reality, competition by rival firms or collusive behavior of potential buyers may further restrict the entrepreneur's bargaining power and prices may result from negotiations. Though biased in favor of the entrepreneur, the model shows that buyers may still profit from advance-purchase (mixed) financing compared to traditional funding. For example, if low income countries are able to enforce a mechanism that guarantees a regular drug price near marginal costs, applying the advancepurchase offer computed above will still enable the entrepreneur to profitably

\footnotetext{
${ }^{16}$ As the pharmaceutical industry exhibits significant elasticities of innovation to expected market size (Dubois et al., 2015), advance-purchase arrangements might provide a valuable tool for screening the profitability of R\&D projects.
} 
fund projects that could not be financed traditionally.

\section{Appendix}

I review the analysis of Sections 3 and 4 for the case of mixed financing in which the entrepreneur cannot commit to rely exclusively on advancepurchase financing for meeting the capital requirement but will use traditional funding sources in order to supplement revenues from pre-orders whenever the project is ex interim profitable, i.e. if inequality (20) is satisfied. I use the same notation as before and focus on the necessary changes to the main Lemmas and Propositions as well as their proofs.

To begin with, note that Lemma 1 and its proof hold without any change if one reinterprets $m_{c}$ as the minimum number of pre-orders that makes the project ex interim profitable for the given prices $p_{c}$ and $p_{r}$, i.e.

$$
m_{c} p_{c}+\left(N-m_{c}\right) \rho\left(p_{c}, p_{r}\right) p_{r} \geq K>\left(m_{c}-1\right) p_{c}+\left(N-m_{c}+1\right) \rho\left(p_{c}, p_{r}\right) p_{r},
$$

where $\rho\left(p_{c}, p_{r}\right)$ denotes the probability that some customer buys at the regular price $p_{r}$ conditional on not having pre-ordered at the advance-purchase price $p_{c}$.

As argued in Section 6, the lack of commitment does not affect the entrepreneur's decision about the regular price $p_{r}$ in stage 2 . Therefore, Lemma 2 and its proof hold without any change, too.

When the entrepreneur decides on the advance-purchase price $p_{c}$ in stage 1, the lack of commitment does not affect his objective function (11) or the relation between the threshold valuation and the advance-purchase price (10) either. It only affects the constraints which determine the minimum number $n$ of pre-orders that is necessary for the project to be realized given a certain advance-purchase price $p_{n}$ : inequalities (6) turn into (21). Thus, the twostep strategy for solving the entrepreneur's maximization problem remains basically unchanged.

As the proof of Proposition 1 is not based on any considerations of the modified constraints (6), it remains valid under mixed financing. Similarly, Proposition 2 remains valid unless the entrepreneur finds it optimal to rely exclusively on traditional funds. Remember that mixed financing includes this possibility as the entrepreneur can deliberately induce that no potential buyer pre-orders by choosing some sufficiently high advance-purchase price.

Proposition 3 basically says that advance-purchase financing outperforms traditional funding for sufficiently large capital requirements. To see that this is also true for mixed financing, reconsider the entrepreneur's strategy to choose an advance-purchase price $p_{N}$ that makes each potential buyer 
pivotal for running the project. The corresponding expected profit (13) is a lower bound for the entrepreneur's optimal profit under mixed financing, too. The relevant constraints (14), however, now become stricter:

$$
N p_{N} \geq K>(N-1) p_{N}+\frac{F\left(p_{N}\right)-F\left(p_{r}\right)}{F\left(p_{N}\right)} p_{r}
$$

As shown in Section 6, the unconstrained solution to the problem of profit maximization is implicitly given by (15) and satisfies the left inequality in (22) for all $K<N$. Moreover, as the right hand side of the second inequality in (22) is strictly smaller than $N$ due to $p_{r}<p_{N}$, the unconstrained solution will meet the right inequality in (22) as well if the capital requirement is sufficiently large. Though it is not trivial to specify a universal threshold for general distributions, an exact analog of Proposition 3 holds for a uniform distribution under mixed financing:

Proposition 5 For any number of potential buyers $N \in \mathbb{N}$, any capital requirement $K \in \mathbb{R}$, and a uniform distribution of valuations the following statements hold:

(a) For any $K \in\left(K_{0}, N\right)$, the project is not realized under pure traditional funding but has a strictly positive probability of realization under mixed financing.

(b) There is some $K_{1} \in\left[0, K_{0}\right]$ such that the entrepreneur strictly prefers mixed financing over pure traditional funding for all $K \in\left(K_{1}, N\right)$.

(c) There is some $K_{2} \in\left[K_{1}, K_{0}\right]$ such that the allocation under mixed financing Pareto-dominates the allocation under pure traditional funding for all $K \in\left(K_{2}, N\right)$.

Proof. For a uniform distribution of valuations, the expected profit (13) from choosing an advance-purchase price $p_{N}$ that makes each potential buyer pivotal is given by $E\left(\pi_{N}\right)=\left(1-p_{N}\right)^{N}\left(N p_{N}-K\right)$ and the critical constraint given by the right inequality in $(22)$ reads $K>(N-1) p_{N}+\frac{p_{N}}{4}$. The unconstrained solution $p_{N}=\frac{K+1}{N+1}$ will satisfy this constraint if and only if $K>\frac{4 N-3}{7}$. In this case, the expected profit equals $E\left(\pi_{N}\right)=\left(\frac{N-K}{N+1}\right)^{N+1}>$ 0 . Otherwise the entrepreneur can set $p_{N}$ arbitrarily close to $\frac{4 K}{4 N-3}$. The corresponding expected profit is then given by

$$
E\left(\pi_{N}\right)=\left(\frac{4(N-K)-3}{4 N-3}\right)^{N} \cdot \frac{3 K}{4 N-3}>0 .
$$


Finally, replacing advance-purchase financing by mixed financing, Proposition 4 and its proof remain valid unless the entrepreneur finds it optimal to rely exclusively on traditional funds.

\section{References}

Belleflamme, P., Lambert, T., and Schwienbacher, A. (2014). Crowdfunding: Tapping the right crowd. Journal of Business Venturing, 29(5):585-609.

Berndt, E. R., Glennerster, R., Kremer, M. R., Lee, J., Levine, R., Weizsäcker, G., and Williams, H. (2007). Advance market commitments for vaccines against neglected diseases: estimating costs and effectiveness. Health Economics, 16(5):491-511.

Berndt, E. R. and Hurvitz, J. A. (2005). Vaccine advance-purchase agreements for low-income countries: Practical issues. Health Affairs, 24(3):653665.

Brito, D. L. and Oakland, W. H. (1980). On the monopolisic provision of excludable public goods. American Economic Review, 70(4):691-704.

Cornelli, F. (1996). Optimal selling procedures with fixed costs. Journal of Economic Theory, 71:1-30.

Dalberg (2013). The advance market commitment for pneumococcal vaccines: process and design evaluation. Full report, Dalberg Global Development Advisors.

Dana, J. D. (1998). Advance-purchase discounts and price discrimination in competitive markets. Journal of Political Economy, 106(2):395-422.

Dana, J. D. (1999). Equilibrium price dispersion under demand uncertainty: the roles of costly capacity and market structure. The RAND Journal of Economics, 30(4):632-660.

Dana, J. D. (2001). Monopoly price dispersion under demand uncertainty. International Economic Review, 42(3):649-670.

Dubois, P., de Mouzon, O., Scott-Morton, F., and Seabright, P. (2015). Market size and pharmaceutical innovation. The RAND Journal of Economics, 46(4):844-871.

Ellman, M. and Hurkens, S. (2016). Optimal crowdfunding design. SSRN Working Paper Nr. 2733537. 
Gale, I. L. and Holmes, T. J. (1992). The efficiency of advance-purchase discounts in the presence of aggregate demand uncertainty. International Journal of Industrial Organization, 10(3):413-437.

Gale, I. L. and Holmes, T. J. (1993). Advance-purchase discounts and monopoly allocation of capacity. American Economic Review, 83(1):135146.

Kumar, P., Langberg, N., and Zvilichovsky, D. (2016). (Crowd)Funding Innovation: Financing Constraints, Price Discrimination and Welfare. SSRN Working Paper Nr. 2600923.

Möller, M. and Watanabe, M. (2010). Advance purchase discounts versus clearance sales. The Economic Journal, 120(547):1125-1148.

Myerson, R. B. (1981). Optimal auction design. Mathematics of Operations Research, 6(1):58-73.

Nasiry, J. and Popescu, I. (2012). Advance selling when consumers regret. Management Science, 58(6):1160-1177.

Nocke, V. and Peitz, M. (2007). A theory of clearance sales. The Economic Journal, 117(522):964-990.

Nocke, V., Peitz, M., and Rosar, F. (2011). Advance-purchase discounts as a price discrimination device. Journal of Economic Theory, 146:141-162.

Norman, P. (2004). Efficient mechanisms for public goods with use exclusion. Review of Economic Studies, 71:1163-1188.

Sahm, M., Belleflamme, P., Lambert, T., and Schwienbacher, A. (2014). Corrigendum to 'Crowdfunding: Tapping the Right Crowd'. Journal of Business Venturing, 29(5):610-611.

Schmitz, P. (1997). Monopolistic provision of excludable public goods under private information. Public Finance/ Finance Publiques, 52:89-101.

Segal, I. (2003). Coordination and discrimination in contracting with externalities: divide and conquer? Journal of Economic Theory, 113(2):147 181.

Strausz, R. (2015). A Theory of Crowdfunding - a mechanism design approach with demand uncertainty and moral hazard. SFB/TR 15 Discussion Paper No. 527. 
Xie, J. and Shugan, S. M. (2001). Electronic tickets, smart cards, and online prepayments: When and how to advance sell. Marketing Science, 20(3):219-243.

Zeng, C. (2013). Optimal advance selling strategy under price commitment. Pacific Economic Review, 18(2):233-258. 